\title{
Positive and Negative Affect: Impact on Empathy and Prosocial Behaviour among College Going Adolescents
}

\author{
Parul Sharma ${ }^{1}$
}

\section{ABSTRACT:}

The positive affect means the different level of moods of an individual on subjective basis such as joy, interest and being alert. It refers to the condition where the individual have positive emotions and feelings involving physiological arousal, thinking process and behaviour. Positive affect also involving the interaction of an individual with the environment and its surroundings. The people shows the characteristics of being full of energy, active, are generally high on positive affect and characteristics like sad, lethargic, stress are examples of the negative affect. Empathy refers to the different kind of experiences. The researchers have defined empathy as ability of a person to feel other's emotions including the feeling and thinking. Therefore it includes an experience that involves understanding others conditions or emotions from their perspective. Empathy increases the prosocial behaviour. The prosocial behaviour means actions which are positive in nature but does benefit others and it includes the moral values, sense of responsibility and does not have any personal gains from such behaviour. It is a kind of voluntary actions that benefits not only the individual itself but also the society as a whole. The aim of the current investigation was to study the impact of positive and negative affect on empathy and prosocial behaviour. For this study, Positive and negative affect scale (PANAS; Watson et al., 1988), Empathy scale (Levine et al., 2009), and Prosocial Tendencies Measure scale (Randall et al., 2003) were administered to the sample of 100 students in the age range of 18-21 years. The sample was taken from different colleges of Chandigarh. An inter-correlation matrix was calculated to see the relationship. The results have shown significant and positive relationship between positive affect, empathy and prosocial behavior. The correlation between positive and empathy is $(r=0.33)$ and positive affect and prosocial behavior is $(r=0.30)$. The significant and negative relationship is found between negative affect, empathy and prosocial behavior. The correlation between negative affect and empathy is $(r=-0.29)$ and negative affect and prosocial behavior is $(\mathrm{r}=-0.27)$. The result is found to be significant at 0.01 levels.

Keywords: Positive and Negative Affect, Empathy, Prosocial Behaviour

Martin (2010) explains the term affect as the experience of feeling or emotions. Therefore the term affect refers to the emotions associated to anything. The emotions or affect can be further divided into the positive affect and negative affect. The term affect refers to the process where there is an interaction of the person with the stimulus.

${ }^{1}$ Research Scholar, Lovely Professional University, Jalandhar

(C) 2015 I P Sharma; licensee IJIP. This is an Open Access Research distributed under the terms of the Creative Commons Attribution License (http://creativecommons.org/licenses/by/2.0), which permits unrestricted use, distribution, and reproduction in any Medium, provided the original work is properly cited. 


\section{Positive and Negative Affect: Impact on Empathy and Prosocial Behaviour among College Going Adolescents}

APA (2006) refers to the term "affect" as a behavior which makes use of different senses such as by facial, vocal and behavior of gestures. Watson and Naragon (2009) elaborate the term positive affect as the positive emotions in humans and their interaction with the environment and surroundings. People who are high on the positive affect are who are alert, have high degree of confidence and are energetic in nature as compared to the people who are low on positive affect generally characterize as distress, sad, lethargic. Clark and Watson (1984) talks on the research on positive affect that it consist of variables which includes the pleasant occasions and events and also the social phenomenon. They further did a research on positive emotions and concluded that individuals high on positive affect are high on energy level, optimistic, and are more likely to be satisfied with their life. Durham et al., (1998) elaborated further on positive emotions and concluded that positive affect is positively and strongly related to the life satisfaction. Cooper \& Deneve (1998) did a research and concluded that these positive and negative affect and life satisfaction are the indicators of the subjective well being. The research concluded that if there is positive mood it will influence the life satisfaction and in turn leads to positive subjective well being but if there is a negative mood it will lead to negative influence on life satisfaction and the subjective well being will be low.

The term negative affect can be described as a personality attribute that consists of negative emotions and poor self concept. Negative affect or emotions include the guilt,, shame, nervousness, anger. Negative affect can be further divided into high and low affect. People who are low on negative affect falls under the category of being calm where people high on negative affect view their world around as in negative sense and negative terms. Negative affect is strongly and negatively correlated with life satisfaction. Individuals who are high on negative affect would have unpleasant views about the world, future and other people around them. The individuals high on negative affect correspond to the people who are high on neuroticism if assessed on the personality factors. The research have also opined that people with negative affect generally have poor coping skills and are generally high on self-reported stress (Wills, 1986).

The recent research by DeGraff (2013) had explained the term empathy as understanding the individual's condition from their perspective therefore, to see yourself in their shoes and to feel as how they would feel in that particular situation. The empathy increases and influences prosocial behaviours. Empathy therefore means the capacity to understand the emotions of others. It not only encompasses the understanding part but also recognizing the emotions of others. Therefore empathy includes the feeling and sharing of other persons emotions. Snyder et al., (2001) did a research and concluded that empathy by some researchers means the ability to see and recognize others emotions while some researchers include empathy as a sense of tenderhearted to the other person.

Prosocial behavior means a behavior that is aimed to benefit others though it is a voluntary kind of behavior. Stephan \& Brief (1986) explained further prosocial behavior that intends to benefit many people and society by means of sharing, co-operation and by the act of being voluntarily involved in a task. It does build positive traits. It prosocial behavior involves inner motivation and altruism. It also involves the unselfish interest in helping out others in various tasks. Cherry (2014) defines prosocial behavior in an article as a series of characteristics that involves the feelings and the thought to give a helping hand for the welfare of others. Nantel-Vivier et al., 


\section{Positive and Negative Affect: Impact on Empathy and Prosocial Behaviour among College Going Adolescents}

(2009) did a research among Canadian and Italian adolescents who aged 10-15 years. The findings indicated that these adolescents were high on empathy and moral reasoning. It was also seen from the study that during the age of adolescence, the youth focus on these behaviors towards their peer groups and society.

In regards to the previous analysis, the adolescent girls have a higher degree of prosocial behavior as compared to the male counterparts. This could be due to the early maturation among females. The recent study have concluded that pubertal timings have found that early maturation among adolescents have found to have a positive effect on prosocial behavior. Gustavo et al., (2012) found a positive correlation of early onset of puberty and prosocial behavior.

\section{OBJECTIVE}

On the basis of aforementioned literature, following objectives have been proposed for the present investigation:

1. To study the relationship between positive affect, negative affect and empathy among college going students.

2. To investigate the correlation between positive affect, negative affect and prosocial behavior among college going students.

3. To study interrelationship between variables under study.

\section{HYPOTHESES}

The purpose of the study was to investigate the role of positive affect and negative affect on empathy and prosocial behavior. Based on the research, following hypotheses were proposed:

1. It is hypothesized that positive affect was expected to be positively related with empathy.

2. It was expected that positive affect was positively related with prosocial behavior.

3. It is hypothesized that negative affect was expected to be negatively related with empathy.

4. It was expected that negative affect was negatively related with prosocial behavior.

\section{METHOD}

The sample consisted of 100 students. The data was collected from the different colleges of Chandigarh. The age range was 18-21 years of B.A., B.SC. \& B.Com. The students in the sample were selected on random basis.

\section{TESTS AND TOOLS}

1. Positive and Negative Affect Schedule (Watson, D., Clark, L.A. \& Tellegan, A., 1988). This scale consist of 20 items. The 10 items consist of positive affect and 
10 items are of negative affect. Each item can be rated from 1-5 where, "1" denotes "very slightly or not at all", " 2 " denotes "a little", " 3 " denotes "moderately", "4" denotes "quite a bit" and " 5 " denotes "extremely at all".

2. Empathy Scale (Levine, B., Spreng, R.N., McKinnon, M.C., Mar, R.A.). The scale consist 16 items. The 8 items were positively scored and 8 items were negatively scored. The positively scored items were rated from $0-4$ where, " 0 " denotes "never", "1" denotes "rarely", "2" denotes "sometimes", "3" denotes "often" and "4" denote "always".

3. Prosocial Behavior Scale (Randall, B.A. \& Carlo, G.). The scale consists of 23 items. The items are scored on the scale of 1-5, where, "1" denotes "does not describe at all", "2" denotes "describe me a little" " 3 " denotes "somewhat describes me", "4" denotes "describes me well", "5" denotes "describes me greatly".

\section{RESULTS AND DISCUSSION}

\begin{tabular}{|l|l|l|l|l|l|}
\hline S.NO. & $\begin{array}{l}\text { Positive } \\
\text { and } \\
\text { negative } \\
\text { affect }\end{array}$ & Positive affect & $\begin{array}{l}\text { Negative } \\
\text { affect }\end{array}$ & Empathy & Prosocial Behavior \\
\hline $\begin{array}{l}\text { Positive } \\
\text { and } \\
\text { negative } \\
\text { affect }\end{array}$ & & $0.77^{* *}$ & $0.90^{* *}$ & $-0.33^{* *}$ & $0.26^{* *}$ \\
\hline $\begin{array}{l}\text { Positive } \\
\text { affect }\end{array}$ & & & $0.43^{* *}$ & $0.33^{* *}$ & $0.30^{* *}$ \\
\hline $\begin{array}{l}\text { Negative } \\
\text { affect }\end{array}$ & & & & $-0.29^{* *}$ & $-0.27^{* *}$ \\
\hline Empathy & & & & & $0.19^{*}$ \\
\hline $\begin{array}{l}\text { Prosocial } \\
\text { Behavior }\end{array}$ & & & & & \\
\hline
\end{tabular}

*value of correlation sign at 0.05 level

$* *$ value of correlation sign at 0.01 level 


\section{Positive and Negative Affect: Impact on Empathy and Prosocial Behaviour among College Going Adolescents}

The first hypothesis that positive affect was expected to be positively related with empathy is proved as the relationship is significantly positive $(r=0.33)$. The second hypothesis that positive affect was positively related with prosocial behavior is also proved as the relationship is significantly positive $(\mathrm{r}=0.30)$. The third hypothesis that negative affect was expected to be negatively related with empathy is proved as the relationship is significantly negative $(r=0.29)$. The fourth hypothesis that negative affect was expected to be negatively related with prosocial behavior is proved as the relationship is significantly negative $(r=0.27)$. Hence all the hypotheses were proved.

The present study aimed to find out the relationship between positive affect, negative affect, empathy and prosocial behavior. Positive affect was found to be significantly and positively correlated to the empathy $(r=0.33)$. The value was significant at 0.01 level. Therefore on the basis of the results that we get from the present investigation, we can say that people who have positive moods have more probability to show the empathy towards others. Likowski et al. (2011) did a research and found out that the participants who had an induction session and had happy moods showed higher empathy than those having sad mood while having induction sessions. Fredrickson (1998) concluded that people who develop positive emotions have higher ratio of developing social relationships and therefore it builds up better and higher quality of interactions in their social world.

Positive affect and prosocial behavior was also found to be positively and significantly correlated $(\mathrm{r}=0.30)$. The value was significant at 0.01 level. In an education portal by Boyd (2014), explains through the research that when the person is in positive, good and happy state of mind, affect and mood, there is a probability that the person would definitely help others. A panel study was done by Thoits and Hewitt (2001) concluded that increase in happiness lead to the increase in prosocial behavior. Many laboratory experiments have also confirmed that prosocial behavior comes from the happy behavior and positive mood.

The relationship between negative affect and empathy was found to be significantly negative $(\mathrm{r}=$ 0.29). The value is significant at 0.01 level. Sadhwani (1990) found out that negative affect has been associated with negative behaviors among adolescents. The study by Roos, Hodges \& Salmivalli (2013) concluded that the negative affect and negative moods such as fear do not lead to the same prosocial behaviors.

\section{CONCLUSION}

The purpose of the study was to find the impact of positive affect and negative affect on empathy and prosocial behaviour. Based on the findings, it was seen that the hypotheses were proved. The positive affect has positive and significant relationship with empathy and prosocial behaviour. The study also proved that negative affect has significant and negative correlation with empathy and prosocial behaviour. The helping behaviour is developed mainly when the person has positive moods but also a person who has negative moods sometimes do involve in helping behaviour so that the mind can be diverted to the other task. So, the individual differences do exist here to say in actual what kind of moods does help in showing empathy and prosocial behaviour. The more research is needed to be done in this area so that the actual scenario could be seen. 


\section{Positive and Negative Affect: Impact on Empathy and Prosocial Behaviour among College Going Adolescents}

\section{REFERENCES}

Boyd, N. (2014). How positive moods and negative state relief affect prosocial behaviour, accessible at: http://education-portal.com/academy/lesson/how-positive-moods-andnegative-state-relief-affect-prosocial-behavior.html\#lesson

Clark, L.A. and Watson, D. (1984). Negative affectivity. The disposition to experience negative aversive emotional states. The journal of psychological bulletin, volume no 96, page no 465-490.

Cooper, H. \& Deneve, K.M. (1998). The happy personality: a meta-analysis of 137 personality traits and subjective well-being. Journal of Psychological bulletin, page no 197-229.

DeGraff (2014). Innovation: Devise with revisionary eyes: as with innovation itself, we are a work in progress.

Durham, C.C., Judge, T.A., Locke, E.A. and Kluger, A.N. (1998). Dispositional effects on job and life satisfaction: the role of core evaluations. Journal of applied psychology, volume no 83 , pages $17-34$.

Fredrickson, B.L. (1998). What good are positive emotions: Review of General Psychology, volume 2, pages 300-319.

Gustavo, C., Crockett, L.J., Jennifer, M.W. and Beal, S.J. (2012). The role of emotional reactivity, self-regulation, and Puberty in Adolescents' Prosocial Behaviors". Journal of Social Development, volume 21, issue no 4, pages 667-685.

Kendra Cherry (2014). What is prosocial behaviour, accessible from: http://psychology.about.com/od/pindex/g/prosocial-behavior.htm

Likowski, K.U., Muhlberger, A., Seibt, B., Pauli, P., \& Weyers, P. (2011). Processes underlying congruent and incongruent facial reactions to emotional facial expressions. Journal of emotions, volume 11, issue no 3, pages 457-467.

Martin, G.N., Hogg, M.A. and Abrams, D. (2010). Social cognition and attitudes. Journal of psychology, Harlow: Pearson education limited, page no 646-677.

Nantel-Vivier, A., Kokko, K., Caprara, G.V. and Tremblay (2012). Prosocial development from childhood to adolescence: a multi-informant perspective with Canadian and Italian longitudinal studies. Journal of Child Psychology and Psychiatry, volume 50, issue no. 5, pages 590-598.

Roos, S., Hodges, E.V.E., \& Salmivalli, C. (2013). Do guilt-and shame-Proneness Differentially predict prosocial, aggressive, and withdrawn behaviours during adolescence? Developmental Psychology.

Sadhwani, A. (1990). Do parenting behaviours moderate the relationship between negative affect, sensory regulation and effortful control?

Thoits, P.A., and Hewitt, L.N. (2001). Volunteer work and well-being. Journal of Health and Social Behavior, volume 42, pages 115-131.

Snyder, C.R., Shane, J. Lopez and Jennifer, T.P. (2011). Positive psychology: the scientific and practical explorations of human strengths, 2nd edition. Los Angeles: SAGE.

Stephan, J.M. \& Brief, A.P. (1986). Prosocial organizational behaviours. The academy of management Review, volume 11, issue no 4, pages 710-725.

Watson, D. And Naragon, K. (2009). Positive affectivity. The encyclopedia of positive psychology, page no 701-711.

Wills, T.A. (1986). Stress and coping in early adolescence: relationships to substance use in urban school samples. Journal of health psychology, volume no 5, pages 503-529. 